\title{
ENTRE NARRATIVAS AUTOBIOGRÁFICAS E POSSIBILIDADES ONTOLÓGICAS DO SER DESDE A EDUCAÇÃO POPULAR: DA REPRESENTAÇÃO AO PROJETO DE SI
}

- JÚLIA GUIMARÃES NEVES

Universidade Federal de Pelotas

VILMAR ALVES PEREIRA

Universidade Federal do Rio Grande

LOURDES MARIA BRAGAGNOLO FRISON

Universidade Federal de Pelotas

RESUMO Este artigo traz um recorte da dissertação de Mestrado em Educação intitulada "Histórias de vida no contexto da Educação Popular: narrativas, projetos de vida e (auto)formação". A pesquisa foi realizada com dezessete educandos do Grupo de Apoio Educacional Maxximus, Curso Pré-universitário Popular, vinculado a um projeto de extensão da Universidade Federal do Rio Grande - FURG, nomeado Programa de Auxílio ao Ingresso nos Ensino Técnico e Superior - PAIETS. A pesquisa desenvolveu-se ancorada na metodologia dos Ateliês Biográficos de Projeto, de Delory-Momberger, com foco na construção dos projetos de vida. A escolha metodológica de análise do corpus de pesquisa incidiu sobre a Análise Textual Discursiva. 0 processo de análise das narrativas escritas dos sujeitos participantes fez emergir, no final do processo, duas categorias. Neste artigo, debruçamo-nos sobre a primeira categoria. 0 trabalho nos permitiu pensar sobre 0 horizonte projetivo do ser em direção à construção daquilo que ele deseja ser. A contribuição da pesquisa aponta para a possibilidade formativa de abertura do passado e de ressignificação das trajetórias de vida em direção ao futuro desejado e projetado no reconhecimento do ser enquanto um sujeito de possibilidades.

Palavras-chave: Educação Popular. Narrativas autobiográficas. Ateliês Biográficos de Projeto. 
ABSTRACT BETWEEN AUTOBIOGRAPHICAL NARRATIVES AND

ONTOLOGICAL POSSIBILITIES OF THE SELF SINCE THE POPULAR EDUCATION: FROM THE REPRESENTATION TO THE PROJECT OF ONESELF

This article brings a snippet from the Master's dissertation in Education entitled "Life stories in the context of Popular Education: narratives, life projects and (self)training". The research was conducted with seventeen students from the Grupo de Apoio Educacional Maxximus, Curso Pré-universitário Popular attached to the extension project named Programa de Auxílio ao Ingresso no Ensino Técnico e Superior - PAIETS from the Universidade Federal do Rio Grande - FURG. The research development was anchored in the Project Biographical Workshops methodology from Delory-Momberger, with a focus in the construction of Life Projects. The choice for the methodological analysis of the research body was based in the Discursive Textual Analysis. The review of the participating student's written narratives revealed two categories in the end of the process, we focused in the first one. This work allowed us to think about the projective horizon of the oneself in the direction of the construction of what he wishes to be. The contribution of this research points to the training possibility of opening the past and the resignification of life pathways in the direction of the desired future, designed with the acknowledgement of the self as a subject of possibilities.

Keywords: Popular Education. Autobiographical Narratives. Project Biographical Workshops. EDUCACIÓN POPULAR: DE LA REPRESENTACIÓN AL PROYECTO EN SI

Este artículo trae un recorte de la disertación de Maestría en Educación intitulada "Historias de vida en el contexto de la Educación Popular: narrativas, proyectos de vida y (auto)formación". La investigación fue realizada con diecisiete alumnos del Grupo de Apoio Educacional Maxximus, Curso Pré-universitario Popular vinculado a un proyecto de extensión de la Universidade Federal de Rio Grande - FURG, nombrado Programa de Auxílio ao Ingresso nos Ensinos Técnico e Superior - PAIETS. La investigación se desarrolló ancorada en la metodología de los Ateliês Biográficos de Projeto, de Delory-Momberger, con enfoque en la construcción de los Projetos de Vida. La 
elección metodológica de análisis del corpus de investigación incidió sobre el Análisis Textual Discursivo. El proceso de análisis de las narrativas escritas de los sujetos participantes hizo emerger, en el final del proceso, dos categorías. En este artículo, trabajamos a partir de la primera categoría. El trabajo nos permitió pensar sobre el horizonte proyectivo del ser en dirección a la construcción de lo que él desea ser. La contribución de la investigación apunta para la posibilidad formativa de abertura del pasado y de la resignificación de las trayectorias de vida en dirección al futuro deseado y diseñado en el reconocimiento del ser como sujeto de posibilidades.

Palabras clave: Educación Popular. Narrativas autobiográficas. Ateliês Biográficos de Projeto.

\section{Palavras iniciais}

\section{[...] biografar implica para o sujeito o direito de ser.}

Passeggi; Abrahão; Delory-Momberger (2012, p. 50)

A construção narrativa de si revela a dialógica entre o ser e a representação do ser. Falar das possibilidades do ser significa mostrar o movimento da narrativa que possibilita ao sujeito representar-se, enquanto anúncio daquilo que é e, ao mesmo tempo, manifestar o projeto que faz de si. Este artigo, ao falar sobre narrativas autobiográficas de representação e projeção de si, procura narrar, mas não se trata de narrar uma única vida, são múltiplas vidas de sujeitos que representaram a si na inventividade daquilo que desejam viver, trazidas na emulsão de um processo interpretativo de produção de novas compreensões.

A pesquisa realizou-se no seio de um curso pré-universitário popular, o Grupo de Apoio Educacional Maxximus, curso pré-universitário popular, vinculado a um programa de extensão da Universidade Federal do Rio Grande - FURG, nomeado Programa de Auxílio ao Ingresso nos Ensino Técnico e Superior - PAIETS. O Grupo de Apoio Educacional Maxximus, possui, em sua estrutura curricular, um momento de desenvolvimento pessoal, a partir da exploração e reflexão sobre a vida, nomeado "Construção dos Projetos de Vida", ancorado na metodologia dos Ateliês Biográficos de Projeto, de Delory-Momberger (2014). É no contexto desse espaço formativo que a pesquisa de mestrado foi gestada e produzida. 0 corpus da pesquisa foi constituído pelas narrativas autobiográficas de dezessete educandos do curso pré-universitário popular.

A Análise Textual Discursiva (MORAES; GALIAZZI, 2013) foi a escolha metodológica para o diálogo com o corpus de análise. Procuramos compreender o percurso de (auto)formação, no contexto das trajetórias de vida narradas, intentando perceber o que se mostra nas construções narrativas realizadas pela turma de educandos do pré-universitário popular Maxximus, em direção aos seus projetos de vida. Proveniente do processo de produção de categorias emergidas do mergulho descritivo e interpretativo no corpus, encontramos a oportunidade de pensar as possiblidades do ser, o que deu origem à primeira, de um total de duas, das categorias finais da pesquisa. A 
segunda categoria final possibilitou reflexões sobre os sentidos do processo (auto)formativo e a convivência transcendente construída na realização de um processo de formação vivenciado na relação com o outro.

Neste ensaio, trataremos da primeira categoria da pesquisa, oriunda do processo final da Análise Textual Discursiva e intitulada "As possibilidades do ser: da representação ao projeto de si". A categoria final comporta três categorias intermediárias, são elas: "o sujeito cansado de si: "quero ser alguém na vida"; "a fragilidade e a fortaleza: o (des)balanço da vida"; "do espaço da experiência ao horizonte da expectativa: consciência da realidade e projeção de si".

Com vistas à organização deste ensaio, apresentaremos os seguintes pontos: I) a paragem, sua forma e seus elementos; II) os caminhos metodológicos da pesquisa; III) o sujeito cansado de si: "quero ser alguém na vida"; IV) "a fragilidade e a fortaleza: o (des)balanço da vida"; v) “do espaço da experiência ao horizonte da expectativa: consciência da realidade e projeção de si"; VI) considerações. Cabe, novamente, destacar que os subtítulos III, IV e V compõem a categoria final de análise do recorte da dissertação trazido neste ensaio.

\section{A paragem, sua forma e seus elementos}

O locus desta pesquisa apostou em uma compreensão do sujeito para além de suas capacidades cognitivas lógicas e racionais. Aqui, o sujeito, educando de um curso pré-universitário popular, é pensando para além do caminho de apreensão de conhecimentos técnicos que garantam a aprovação em um exame de seleção ao ingresso no ensino superior. Trata-se de um curso inserido em um programa de extensão universitária que constrói práticas formativas orientadas pelos princípios da Educação
Popular, concepção de formação humana que assume a indispensável relação entre campo educativo e classe social. Dessa maneira, está comprometida com a denúncia da sociedade excludente, cindida em classes sociais, e o anúncio das possibilidades de transformação através da mobilização política e crítica dos sujeitos da classe popular nos setores da sociedade.

O Programa de Auxílio ao Ingresso nos Ensinos Técnico e Superior - PAIETS reúne oito cursos pré-universitários, em três cidades gaúchas, distribuídos da seguinte maneira: seis cursos pré-universitários populares na cidade do Rio Grande/RS, um curso pré-universitário popular em São José do Norte/RS e um curso pré-universitário popular em Capão do Leão/RS. Estes cursos contam com a atuação voluntária de educadores populares (sendo a maioria estudantes universitários e alguns membros da própria comunidade), abarcando os sonhos e as esperanças de jovens e adultos que pensam suas vidas conjugadas à conquista de ingresso no Ensino Superior. O PAIETS, visando, entre outros aspectos, o ingresso nos Ensinos Superior e Técnico, pretende proporcionar à comunidade, aos sujeitos oriundos das camadas populares, a possibilidade de estudo em uma universidade.

Um dos seis cursos localizados na cidade do Rio Grande/RS é o Grupo de Apoio Educacional Maxximus, locus da pesquisa aqui narrada. O Maxximus é um curso que completou, em 2016, oito anos de trajetória vivenciada na parceria com uma escola estadual da cidade do Rio Grande/RS, a Escola Estadual de Ensino Médio Brigadeiro José da Silva Paes, que sede o espaço físico para a realização dos encontros do curso. Desde 2011, a organização curricular do curso abarca a disciplina que tem como nome "Construção dos Projetos de Vida". Desta forma, há 5 anos, acompanhando as diferentes áreas do conhecimento que 
compõem os encontros realizados pelo curso, a turma de educandos, em aproximadamente duas horas semanais, é convidada a construir um momento de encontro consigo, na partilha com o outro, dando origem aos Ateliês Biográficos de Projeto de Delory-Momberger (2014), modelados para a realidade do pré -universitário popular.

\section{Os caminhos metodológicos da pesquisa}

O tempo de convívio com o grupo no curso pré-universitário popular, bem como o número de educandos comportado por tal contexto, ambos distinguem-se daqueles sugeridos por Delory-Momberger (2014), ao propor a metodologia dos Ateliês Biográficos de Projeto. Os ateliês, no curso pré-universitário popular, deram formato à disciplina intitulada "Construção dos Projetos de Vida", e nessa construção adaptações metodológicas foram realizadas.

A disciplina "Construção dos Projetos de Vida" foi vivenciada, semanalmente, ao longo dos meses de março a outubro do ano de 2014 - ano de realização da pesquisa, com uma turma composta por dezessete educandos. Delory-Momberger (2014) nos mostra a indicação de um grupo formado por até doze pessoas, em uma construção de ateliê com duração próxima a três meses, contemplando seis etapas, seguidas por um processo avaliativo, etapas que podem ser compreendidas, resumidamente, em: I) informações aos partícipes sobre as etapas dos ateliês, fala social de engajamento ao grupo, fixação da regra de descrição sobre o que é narrado e a compreensão sobre os sentidos do movimento proposto sobre a vida, na intenção da projeção do futuro, na relação dialética com o passado; II) elaboração, negociação e ratificação coletiva do contrato biográfico, fixan- do as regras de funcionamento e a intenção autoformativa do ateliê, de relação consigo e com o outro; III) construção da 1a narrativa, com eixo temático apresentado pelo formador; IV) exploração da 1a narrativa em grupos formados por três pessoas - tríades e incentivo à produção da segunda narrativa, produzida após reflexão da escrita inicial coexplorada na relação com o outro; $v$ ) socialização da 2a narrativa no grande grupo, registrada por um colega chamado escriba, eleito pelo autor da narrativa. 0 escriba escreve a narrativa em primeira pessoa e entrega ao autor com o incentivo à elaboração da 3a narrativa - contendo o projeto pessoal; VI) momento de síntese, do anúncio e exploração dos projetos pessoais nas tríades e na sequência no grande grupo; após esta etapa ocorre um encontro dedicado à reflexão sobre o balanço do impacto formativo do ateliê e a avaliação do processo. A primeira e segunda etapas ocorrem em uma mesma jornada. Em um intervalo de duas a três semanas é chegado o momento da terceira e quarta etapas, realizadas em dois dias. Entre estas etapas e a quinta etapa e entre a quinta e a sexta etapas há um intervalo de duas semanas e, para a realização do encontro sobre a incidência formativa do ateliê, há um intervalo de um mês.

No contexto do curso pré-universitário popular, as sete etapas dos ateliês estiveram organizadas sob a forma de dois ciclos de atividades: I) o primeiro ciclo voltado para a identificação, a doação e o comprometimento de todo o grupo em relação à proposta e à construção das primeiras narrativas de abertura e encontro com o outro, o que podemos compreender como representação das etapas I, II e III dos ateliês de Delory-Momberger; II) o segundo ciclo, comportando as construções das narrativas orais e escritas nos pequenos grupos - tríades - e no grande grupo, perpassando as trajetórias de vida (trajetória da in- 
fância, trajetória da adolescência, trajetória escolar, trajetória familiar), relaciona-se com as etapas III, IV e V da autora, realizadas aqui de forma recursiva, até o trabalho com as quatro seções da existência - infância, adolescência, trajetória escolar e familiar. Após essas construções, há a exploração dos projetos de vida, correspondendo à etapa VI da proposição dos ateliês. Nesta experiência, a etapa III é assumida em dois horizontes. Um destes horizontes é voltado à produção de narrativas de aproximação do outro, sobre o estar ali, em um curso pré-universitário popular, buscando produzir seu projeto de vida, iniciado, esboçado, planejado naquele espaço. Outro horizonte, dedicado às construções narrativas sobre as seções da vida, nos permite compreender a presença da etapa III nos dois ciclos de atividades. 0 encerramento do segundo ciclo é feito através do processo avaliativo do percurso formativo vivenciado, alusivo ao último encontro dos Ateliês Biográficos de Projeto.

Cada educando possuía uma pasta onde guardava as construções narrativas produzidas durante todos os encontros. O cômputo das narrativas dos dezessete educandos deu formato ao corpus empírico da pesquisa. No desafio de compreensão e construção de sentidos às narrativas, escolhemos a metodologia denominada "Análise Textual Discursiva", de Moraes e Galiazzi (2013).

Acreditamos que as pesquisas emergentes do método (auto)biográfico e a metodologia de análise de dados proposta pela Análise Textual Discursiva dialogam, ao não pretenderem a testagem de hipóteses (a fim de refutá-las ou comprová-las) ao final de um processo de pesquisa. O que importa, aqui, são os processos interpretativos pelos quais o pesquisador busca aventurar-se. A Análise Textual Discursiva inscreve-se como metodologia de análise que trabalha sob a construção discursiva, investindo etapas sucessivas de: produção de unidades de sentido e reunião das unidades em categorias iniciais - primeiros agrupamentos - seguido das categoriais intermediárias e finais. As categorias finais dão origem a um metatexto, que reúne a descrição do processo que a faz emergir, aliado ao movimento interpretativo realizado pelo pesquisador, que convoca "comunidades argumentativas" (MARQUES, 2006), para tecer um diálogo teórico com o empírico.

Neste sentido, trazemos na sequência desta escrita uma construção textual que apresenta a primeira categoria final de análise, de um total de duas categoriais finais oriundas do processo de análise da pesquisa. Brevemente, como um modo de apresentar as reflexões produzidas, fazemos saber sobre as categorias intermediárias que originaram esta categoria final. A primeira delas diz respeito ao desejo de ser "alguém na vida". Esta categoria intermediária apresenta uma leitura sobre o sujeito que está cansado de si, isto é, aquele que anuncia um sentido existencial localizado no futuro e traduzido pelo ingresso no Ensino Superior. O encontro das histórias de fortaleza e de fragilidade marca o desenvolvimento da segunda categoria intermediária. Nessa construção, os sujeitos inscrevem-se a si mesmos e produzem, da vida, suas histórias de vida. Concluímos esta categoria final com a categoria intermediária que apresenta o horizonte projetivo do sujeito, que demonstra o movimento que vai da experiência ao projeto de si. É no somatório das três categorias intermediárias que temos a primeira categorial final da pesquisa. Lembramos que, ao final da pesquisa, chegamos a duas categoriais finais, porém, dado o limite textual do artigo, optamos por trazer apenas a primeira categoria final de pesquisa.

Cabe ressaltar que não trazemos a intenção de produzir verdades sobre as narrativas, 
tampouco interpretações estanques, fixas e invariáveis, sobre as escrituras empreendidas na pesquisa. Produzimos interpretações em diferentes tempos presentes, a contar os múltiplos dias em que nos debruçamos para a realização da análise dos dados da pesquisa. Este presente, bem sabemos, muda constantemente. Os pseudônimos mencionados ao longo do texto referem-se às formas de se nomear escolhidas pelos sujeitos da pesquisa.

\section{O sujeito cansado de si: "quero ser alguém na vida"}

Não sou nada.

Não serei nada.

Não posso querer ser nada.

À parte isso, tenho em mim todos os sonhos do mundo.

Fernando Pessoa (1996, p. 61)

O poeta português, Fernando Pessoa (18881935), em seu poema $A$ tabacaria (PESSOA, 1996, p. 61), relaciona dimensões que, aparentemente, são antagônicas na descrição de um si mesmo. Como pode não ser nada, não ser um nada em relação ao futuro, não poder querer ser nada e, ao mesmo tempo, carregar em si todos os sonhos do mundo? No caso desta categoria intermediária, encontramos nas narrativas um sujeito que aparenta sentir-se um nada, ou seja, um ser que se mostra cansado de si, cansado de ser o que é.

Agora, se voltarmo-nos ao poema de Pessoa, com especial atenção ao trecho em que o poeta nos diz que tem em si todos os sonhos do mundo, de repente, ficamos em dúvida com relação ao sentido de sua reflexão existencial: afinal, o não sou nada não seria um modo de dizer "não me reduzam a nada"? Com este olhar, pode ser que as narrativas que afirmam o "ser nada" estejam, tal como a abertura de $A$ tabacaria, a prelibar o dizer sobre o devir do sujeito que, ao mesmo tempo, querendo ser alguém na vida, carrega consigo todos os sonhos do mundo.

As frases que contêm os trechos que remetem ao querer ser alguém na vida formulam incógnitas. Por que alguém se compreende como não sendo alguém? O que é ser alguém? De onde vem a ideia de não ser alguém? A nossa primeira intuição é a de que, querendo ser outros que não o que são, os sujeitos estão, por suas condições existenciais, cansados de si. Para exemplificar, tomemos como exemplo um trecho de uma das narrativas de Faísca: “para no futuro eu ser alguém na vida, e é por esse motivo que eu gosto de estudar. Para dar orgulho a minha mãe e ela entender que eu posso ser alguém na vida". o que vemos aqui é o projetar-se em direção a um futuro que seja diferente do presente. Há um sujeito que quer ser alguém, que quer ser motivo de orgulho, que quer mostrar para si e para o outro que o porvir do tempo a fará diferente. Entretanto, Faísca ainda não nos deu a chave para a compreensão quanto à origem do querer "ser alguém", mas vemos que o presente a mantém condicionada a ser o que ela não pretende continuar sendo.

Ao insistirmos na busca pela compreensão do sujeito cansado de si, encontramos outro indício nas palavras de Rihana. Ela nos diz o seguinte: "na minha infância, eu pensava muito em ser alguém na vida, ter uma profissão valorizada e que eu gostasse da minha escolha profissional". Se Faísca menciona que o motivo pelo qual gosta de estudar é porque isso é o que possibilitará a ela ser alguém na vida, Rihana assimila o querer ser alguém na vida, desejo que a acompanha desde a infância, a ter uma profissão valorizada. Até aqui, parecenos que o que Faísca e Rihana têm em comum não é só o desejo de ser alguém, mas o percurso que thes possibilitará ser alguém.

No mesmo sentido das exposições anteriores, Letícia quer "estar na universidade para 
ser uma pessoa importante". Nesses termos, Faísca, Rihana e Letícia concebem um caminho possivel para ser alguém na vida. Há um tripé que, mesmo composto de elementos distintos, complementa-se para fundir um caminho de possibilidades. Assim, a continuidade dos estudos, na fala de Faísca, o ser profissional, dito por Rihana, e o ingresso na universidade, mencionado por Letícia, todos compõem a tríade da superação do sujeito cansado de si.

Em se tratando dos estudos, no sentido da escolarização, o próximo passo para os educandos do pré-universitário popular Maxximus é o ingresso na universidade. Portanto, a projeção que os sujeitos fazem de si está, direta ou indiretamente, relacionada com a universidade. A busca pelo ingresso na universidade tem uma fonte, e é aí que se revela, uma vez mais, a trilha que os fará "alguém na vida".

Se colocarmos em linha uma espécie de percurso hipotético a ser trilhado pelos educandos do Maxximus, mesmo sabendo que as trajetórias de vida não são lineares, o tripé, que antes encontramos, estaria assim relacionado: primeiro, com a narrativa de Faísca, a figuraforma do indivíduo cansado de si, que almeja "ser alguém" e que, de certa forma, anuncia o estudo como condição para tal; segundo, o conhecimento de si que é produzido a partir de um passado revisitado, tal como o fez Rihana, ao dizer que já na infância queria "ser alguém", ter uma profissão valorizada; terceiro, a constatação feita por Letícia em relação ao papel da universidade para que ela seja uma pessoa importante. Mesmo com a particularidade de cada fala, concluímos que nos três casos há um "querer ser" que parte de "um não ser". Assim, o estudo, a profissão e a universidade são os elementos mediadores da relação entre o sujeito cansado de si e o sujeito esperançoso de si, aquele que quer "ser alguém na vida".

Mesmo diante destas reflexões, ainda não encontramos a origem daquilo que faz com que os sujeitos estejam cansados de si. Por que o estudo, a profissão e a universidade são as palavras-chave dessas narrativas? Será que esse querer "ser alguém", que não a si mesmo, não está no fato dos autores dessas narrativas serem o sujeito marginalizado na sociedade? Em outras partes das narrativas aparecem trechos onde os sujeitos se reconhecem pertencentes à classe popular e, a partir desse reconhecimento, sentem-se à margem de outras possibilidades de ser. Em outro trecho das narrativas de Rihana, é possivel identificarmos a questão da classe popular e, novamente, em outro termo, a menção à profissão. Vejamos: "convivo em uma sociedade capitalista, por isso me incluo na classe popular, porque cresci vendo meus parentes trabalharem para obterem um futuro melhor". Nesse trecho, Rihana nos mostra o locus de sua vida e a constatação lúcida de que é necessário trabalhar para obter um futuro melhor. É por esta razão que desde a infância Rihana sonha com a profissão. Além disto, ela aponta para outra questão importante, que é o reconhecimento de que vivemos em uma sociedade cindida em classes. Aproveitemos esta deixa para trazer um trecho de uma das narrativas de Persistir. Ele nos diz o seguinte: "os meus condicionantes são ser da classe baixa popular". Essa colocação parece corroborar com a colocação feita por Rihana. Persistir está a anunciar o que o condiciona, do mesmo modo que a colega assemelha à tarefa de seus familiares que, trabalhando, buscam um futuro melhor. Tanto para Rihana quanto para Persistir é necessário romper com a condição existencial atual. Persistir não disse como romper, mas Rihana acredita que a ruptura está na profissão.

É diante do reconhecimento de que estão inseridos em um cenário social bipartido, a partir da identificação sobre de que lado estão, que os educandos do Maxximus inscrevem seus futuros. Esse futuro projetado revela o 
desejo por um viver em uma outra condição, diferente das atuais. Em outro trecho de uma das narrativas de Faísca, parece-nos que ela faz uma síntese entre a sua atual condição existencial, enquanto classe social, e o futuro, que nada mais é do que algo que poderá torná-la diferente: "eu estou na classe popular porque vejo o futuro distanciado de mim". Em outros termos, Faísca nos revela que, para ela, pertencer à classe popular significa ter um futuro remoto, oculto, vedado. Com a colocação feita por Faísca, podemos concluir duas reflexões: I) o sujeito cansado de si está cansado é das poucas possibilidades de ser o que almeja; II) resta o reconhecimento de que, mesmo com um futuro que se distancia, ainda há um futuro.

Até este momento, de acordo com a interpretação que vimos fazendo dos trechos das narrativas, podemos perceber que no sujeito da classe popular está internalizado o sentimento de ser nada. Entre outros, este sentir denuncia as razões pelas quais aparece, nas narrativas, o sujeito cansado de si. Nesta senda, trazemos o trecho de uma narrativa produzida por Amanda, que encaminha a nossa reflexão para a relação estabelecida entre o sujeito cansado de si e o papel transformador da universidade. A potência da transformação, que reside em vigília na universidade, não está apenas na vida individual desses sujeitos, mas na condição existencial da classe popular. Nas palavras de Amanda: "o ingresso na universidade significa muito para mim, por diversos motivos. 0 primeiro seria a realização de um sonho que eu tenho desde muito cedo, sempre quis ser diferente da realidade das pessoas que convivo". A narrativa de Amanda soma-se às reflexões estabelecidas anteriormente, em diálogo com os trechos das narrativas de seus colegas. Podemos destacar a passagem em que Amanda quer uma realidade diferente da que é comum entre as pessoas do seu convívio. Neste sentido, o ingresso na universidade é uma das possibilidades de mudança; é a fronteira que divide o sujeito cansado de si e as possibilidades do sujeito que poderá ser diferente daquilo que são as pessoas de seu convívio, ou seja, que encontrará a condição existencial que trará para si o sentimento de "ser alguém" na vida.

Outro elemento a ser pensado é quanto ao reconhecimento dos sujeitos oriundos da classe popular sobre a existência de classes sociais antagônicas. Para o sujeito cansado de si, é como se aqueles que estão do outro lado, ou seja, os que não estão na classe popular, tivessem o seu futuro próximo e próspero. Relembrando Freire (1987), essa relação latente da sociedade de classes, que é o vínculo estabelecido entre opressores e oprimidos, inculca no oprimido o mito de permanência em limitados espaços por que de origem popular. Assim, o ingresso na universidade deflagra, no sujeito da classe popular, a viabilidade de chegar ao outro lado desta sociedade binária, junto daqueles que são vistos na proximidade de seus futuros projetados. Por esta razão, a universidade, que pode significar o encontro do sentido da própria existência dos sujeitos da classe popular, está na encruzilhada: l) porque de um lado temos o desejo dos sujeitos da classe popular de nela ingressarem para não mais se sentirem "nada" e, assim, transformarem suas realidades de vida; II) de outro lado, o risco iminente de que o sujeito da classe popular se distancie de seu interesse coletivo, já que os cursos universitários pouco têm a ver com as necessidades e os interesses das massas. Estes sujeitos populares buscam a universidade na intenção de mudarem sua vida e a realidade de seu entorno, mas nos espaços dos cursos universitários está a produção de conhecimentos para o mercado de trabalho postos a serviço das mi- 
norias privilegiadas. Cristóvão Buarque (2003, p. 34-35) revela-nos indicativos deste cenário, ao afirmar que:

Os cursos de Economia buscam maneiras de aumentar a riqueza e, em raros casos, estudam a superação da pobreza. Os cursos de Medicina estão mais interessados em não deixar que os ricos morram ou envelheçam do que em evitar a mortalidade infantil. Os arquitetos se preocupam em construir mansões e edificios para os ricos, e quase nuca pensam em soluções para os problemas habitacionais dos pobres. Os cursos de Nutrição dão mais ênfase a emagrecer os ricos do que a engordar os pobres. Todos os campos da educação superior ignoram a grande massa da população, tanto por omissão quanto pela ação. A sociedade optou pela exclusão.

Partindo da provocação feita por Buarque (2003), queremos pensar sobre o protagonismo exercido pelos jovens da classe popular, enquanto "atores na inovação política e social" (MELUCCl, 2007, p. 43) que, quando universitários, poderão problematizar a realidade (im)posta no/pelo espaço da universidade, sobretudo, porque há a possibilidade de perceberem que o ideal de formação destoa de seus anseios iniciais pelos quais eles buscam o ingresso ao Ensino Superior.

\section{A fragilidade e a fortaleza: o (des) balanço da vida}

O drama de uma vida sempre pode ser explicado pela metáfora do peso. Dizemos que temos um fardo nos ombros. Carregamos esse fardo, que suportamos ou não, lutamos com ele, perdemos ou ganhamos. [...]. Seu drama não era $o$ drama do peso, mas da leveza. $O$ que se abatera sobre ela não era um fardo, mas a insustentável leveza do ser.

Milan Kundera (2008, p. 121-122)

Nas narrativas que deram origem a esta categoria, encontramos a realização de um movimento que produz, metaforicamente, uma mistura de si, ora heterogênea e ora homogênea, marcada por superficies de fragilidade e superficies de fortaleza. Produzir uma mistura homogênea da vida, a partir do exercício narrativo, significa identificá-la de duas formas, conforme a relação metafórica que estabelecemos: I) a fortaleza ou a fragilidade como marcas únicas, ou seja, na ressignificação das trajetórias de vida só uma dessas dimensões é reconhecida; II) a fragilidade $e$ a fortaleza tão misturadas, tão cheias disso e daquilo, que é impossivel separá-las e dosá-las, dizendo se há mais ou se há menos de uma ou outra. Na sequência da metáfora, fazer da vida uma mistura heterogênea é identificar, ao narrar, o quanto de fragilidade e/ou o quanto de fortaleza há nas experiências que compõem as trajetórias de vida.

Os escritos do tcheco Milan Kundera (1929), citado em epígrafe, provocam-nos a pensar sobre o drama do peso e o drama da leveza, que poderá instaurar a existência e/ou a coexistência do pesado e do leve, do sucesso e do fracasso, da alegria e da tristeza, da esperança e da desesperança na vida, dimensões que marcam os itinerários existenciais. Neste sentido, quando nos reportamos à duplicidade do (des)balanço da vida, queremos retratar o movimento feito pelos sujeitos sobre a produção de aprendizagens acerca das superficies de fortaleza e de fragilidade. Tratamos o balanço como o processo que possibilita ao sujeito perceber a produção de fortalezas a partir do ato reflexivo sobre as experiências de vida interpretadas como fragilidades. 0 desbalanço da vida é aquilo que faz com que o sujeito não perceba a sua vida como movimento e não consiga identificar um devir de possivel superação. Em outras palavras, o desbalanço acaba por tolher o aprendizado que a experiência negativa pode proporcionar, já que é este aprendizado que garante a compreensão da vida como balanço. 
Esta catalogação, do que é o balanço e do que é o desbalanço da vida, permite-nos fazer uma relação com a caracterização dada por Josso (2010), ao nomear experiências fundadoras. As experiências fundadoras referemse àquelas identificadas como experiências orientadoras ou reorientadoras do percurso de vida "que, em boa parte, são constituídas pela narração de microssituações (designadas, às vezes, por episódios significativos)" (JOSSO, 2010, p. 214). Assim, a narrativa, enquanto processo de formação e de conhecimento, introduz a compreensão das experiências fundadoras que implicam percursos de transformações que marcam a existência humana. Estas experiências podem produzir as interpretações das superficies de fragilidade e das superfícies de fortaleza; por isso, as experiências fundadoras podem provocar o balanço ou o desbalanço da vida.

Nas narrativas, encontramos movimentos de junção, ou seja, amarrações que remetem ao balanço e demonstram a coexistência potencial da fortaleza e da fragilidade, tal como narrado por Lesiane, ao explicar os "altos" e "baixos" da sua vida:

Com mais altos que baixos, mas os baixos bem doloridos e preocupantes levados por perdas e decepções. Altos representados por compreensão, apoio, carinho. Uma conquista na minha vida foi me ver uma pessoa mais responsável e estudiosa. No 1o ano do ensino médio fiquei em exame em física e com isso levei um susto muito grande que a partir desse momento me tornei uma pessoa diferente.

Lesiane produziu, a partir da sua vida, uma narrativa que retrata uma mistura heterogênea. Ela identifica as suas fragilidades e as suas fortalezas, dosando-as. Reconhece, nesta apuração, mais altos do que baixos e, ao narrá -los, Lesiane estabelece relações. Da reprovação em física, que pode ser interpretada como uma experiência fundadora, ela retira o apren- dizado que a faz, no presente, reconhecer-se mais responsável e estudiosa. Essa experiência, a partir das aprendizagens sobre ela construídas, permite-lhe produzir o balanço de sua vida.

Além dos casos em que identificamos os movimentos de junção, também apontamos momentos de disjunção. Nestes casos, a narrativa produz uma história de vida de rupturas que promovem o desbalanço da vida. Como exemplo, trazemos a narrativa de Alicia Keys. Vejamos: "uma tristeza que lembro é não ter passado na minha primeira prova do ENEM. Sou uma pessoa muito realista, acabo muitas vezes desistindo do que eu quero porque já acho que vai dar tudo errado". No trecho narrativo de Alicia Keys, ela traz a reprovação no ENEM como experiência fundadora que, como todas as experiências classificadas como fundadoras, "contém uma carga emocional muito forte que deixou uma 'marca' (ou mesmo um traumatismo), com a qual a pessoa foi estimulada a 'fazer qualquer coisa"' (JOSSO, 2010, p. 214). É importante lembrarmos que as cargas emocionais produzidas nas microssituações permitem a transformação dos acontecimentos da vida em experiências. O acontecimento da reprovação provocou em Alicia Keys a construção de uma narrativa de mistura homogênea, marcada pela transformação deste acontecimento em experiência que produz fragilidade, superficie que ela identifica nesta mistura, ao não acreditar que as suas buscas possam dar certo. Neste primeiro momento, não identificamos a fragilidade como potência, como possibilidade de aprendizagem formativa, mas como desbalanço que a impede de pensar diferente.

Agora, trazemos a narrativa de Flora, que difere da narrativa de Alicia Keys, sobretudo por produzir junções. As experiências de fragilidade não fazem com que Flora desbalance sua vida, pois ela demonstra a possibilidade 
de superação do que está posto. Flora narra a sua vida, dizendo: "sou uma pessoa realista e vou até o último. Já passei por várias coisas que minha autoestima já foi embaixo, mas sempre tenho em mente que uma hora vai passar e tudo vai ficar bem e eu vou conseguir tudo o que estou planejando". De maneira próxima, Alexia explana a forma como se coloca diante dos acontecimentos dificeis na orientação tomada frente ao decurso da vida. Notemos: "estou com dificuldades, mas com a autoestima alta. Lido com perdas como algo que me faz fortalecer e querer cada vez mais aquilo". Flora e Alexia fazem da fragilidade fonte de fortaleza; na identificação de intempéries não consentem deixar de produzir o balanço de suas vidas.

Em narrativa semelhante à de Flora e Alexia, Dory registra o reconhecimento de algumas fragilidades. Em suas palavras, ela cita experiências fundadoras: "meus problemas com bulimia e tristeza me atrapalharam muito e ainda sinto as cicatrizes". Mas isso não a faz esmorecer. Em outro trecho, ela escreve: "sou feliz do meu jeito, e a música e a poesia me ajudaram muito". Dory produz a reflexão de sua vida interpretando-a como uma mistura homogênea, diferente da produzida por Alicia Keys. No caso de Dory, coexistem superficies de fragilidade e superficies de fortaleza. Os dois fragmentos dessa narrativa são sequenciais, mostrando que, partindo das tristezas e cicatrizes, Dory encontra na música e na poesia a maneira com que ela consegue dizer de si: "sou feliz do meu jeito".

As narrativas, enquanto aprendizagens da própria existência, demonstram os modos de ser e estar na vida e as relações que mantêm consigo no vaivém entre os acontecimentos da vida. Faísca, ao pensar sobre a totalidade de sua vida, escreve: "eu vejo minha vida como uma totalidade de harmonia e poucas vitórias". Parece-nos que Faísca produz da sua vida uma mistura heterogênea, onde identifica que há harmonia e poucas vitórias, como duas superficies distintas de uma mesma mistura. É como se a fortaleza estivesse na harmonia que ela identifica em sua vida. Faísca não nos diz que harmonia é essa, mas compreendemos que ela está no contraponto do reconhecimento das poucas vitórias. É como se a existência de poucas vitórias simbolizasse a fragilidade.

No intento de esboçarmos o somatório de trajetórias que compõem a vida, trazemos a narrativa do Futuro Professor, exemplificando a representação de si pautada na compreensão por ele escrita sobre o balanço de sua vida, no transcorrer do tempo. Esta narrativa é um registro escrito, realizado através da atividade na qual cada educando recebeu um pedaço de barbante. Esta atividade compôs o primeiro ciclo de atividades da disciplina "Construção dos Projetos de Vida". O barbante simbolizava, naquele contexto, a vida de cada um. E se fôssemos representar nossa vida, até este momento, como a representaríamos? Como podemos representar o percurso de vida através deste barbante? o que buscava ser representado era o percurso de formação em sua totalidade, compreendendo que "a trama geral serve não apenas como ponto de referência para situar a reflexão específica na continuidade temporal do autor, mas permite igualmente amplificar as primeiras articulações encontradas" (JOSSO, 2010, p. 149).

A trama geral da vida, expressa no barbante, fundou o trabalho reflexivo de construção de significados sobre o emaranhado de trajetórias que compõe o percurso de uma vida. Nesta atividade, procuramos demostrar a vida percebida em sua totalidade, na maneira como foi disposto e fixado o barbante em uma folha de papel, ramificado ou contínuo, com emendas, dobras ou nós. 
Figura 1 - Construção narrativa do Futuro Professor sobre a totalidade da vida. Fonte: Acerto pessoal.

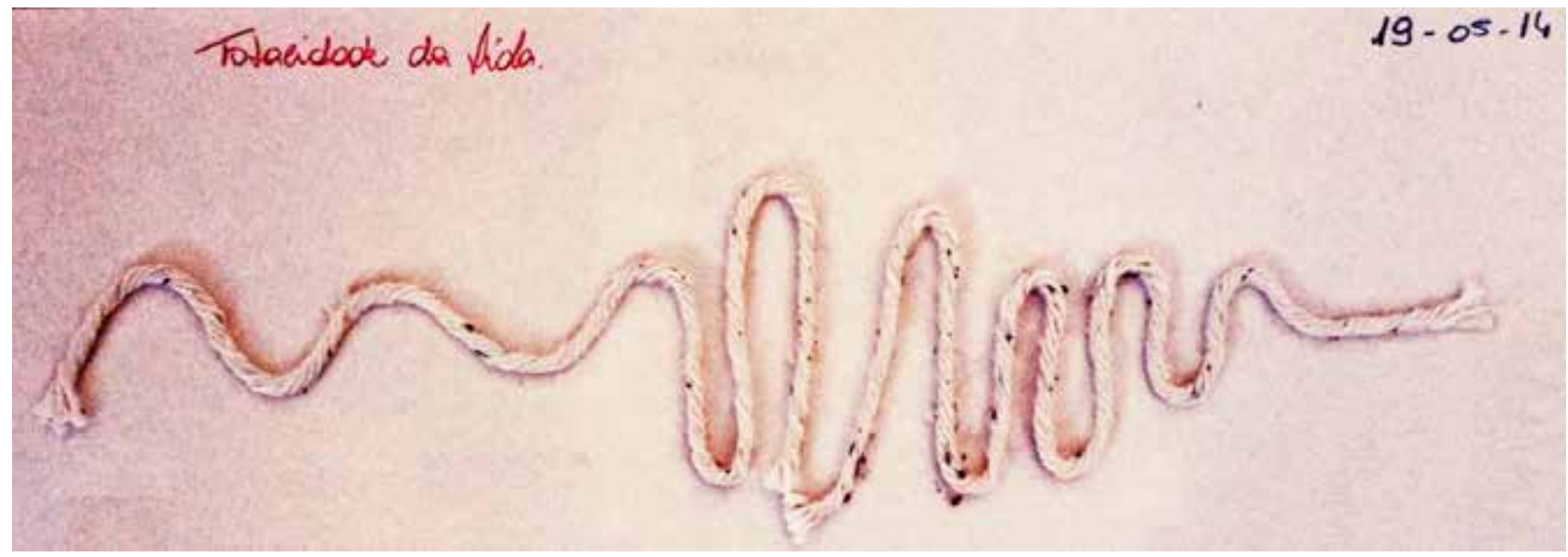

Se analisarmos a primeira parte do barbante, que se refere à infância, podemos associar sua forma como a de um escorregador, onde a criança desliza aos poucos para a sua adolescência. Porém, com toda a inocência e alegria que flui nesta fase, aqui é descoberta. Subindo os degraus, sentamos, e nos jogamos por este brinquedo, sempre com a vontade de subir de novo. Na segunda fase, nos deparamos com os altos e baixos que a vida apresenta. Quando descemos, muitas vezes temos dificuldades para subir novamente, sem aquela energia que tínhamos quando crianças. E depois de passar por esta etapa de descobertas (seja de maneira fácil ou dificil) continuamos nessa linha que sobe e desce, pois vem os deveres substituindo as responsabilidades: de manter-se em um emprego, de adquirir bens, de construir uma familia, casar, ter um bom futuro. Aí entram várias coisas que nos tiram do sério e fazem esta linha continuar subindo e descendo. Na terceira fase é onde conseguimos alcançar um ponto de equilíbrio. Paramos e olhamos para tudo que fizemos e construímos na nossa vida. E vemos que com todos aqueles obstáculos, tudo o que passamos e aprendemos. E depois de assistir esse filme da vida, podemos descansar em paz, com a certe$z a$ de que vivemos com os nossos batimentos sempre ativos, pois com uma vida em linha reta, ninguém realmente vive...

A narrativa do Futuro Professor revela a intenção de fazer da vida uma história, como possibilidade de contornar o vivido, evidenciando suas esferas existenciais. Ao representar-se, o Futuro Professor constrói uma narrativa gené- rica que demonstra a compreensão por ele empreendida, ao abranger a totalidade da vida nas trajetórias da infância, adolescência e da vida adulta. O Futuro Professor é um adolescente. A escrita desta narrativa aconteceu aos seus 16 anos de idade. Ele ainda não chegou a alguns dos pontos que cita em sua narrativa, do filme da vida, como a nomeia, mas ele os representa como imagina que sejam, com as contingências que pontuam a temporalidade da vida. Assim, o Futuro Professor produz, projetivamente, o balanço de uma vida. Reportamo-nos a Milan Kundera (2008, p. 11), em outro fragmento de sua obra $A$ insustentável leveza do ser, quando ele diz: "o mais pesado dos fardos é, portanto, ao mesmo tempo a imagem da realização vital mais intensa. Quanto mais pesado é o fardo, mais próxima da terra está nossa vida, e mais real e verdadeira ela é". Os fardos são entendidos como a realização vital mais intensa, que fazem da vida autêntica. De forma semelhante, vimos representando a balanço da vida como processo que possibilita ao sujeito produzir fortalezas a partir das fragilidades. As fragilidades, aludidas como potenciais formativos, referemse, em Kundera, à realização vital mais intensa. Análogo a isso, na narrativa do Futuro Professor, há uma compreensão de que na medida em que a vida "sobe e desce" está a materialização do próprio viver, pois com uma vida em linha reta, ninguém realmente vive. 
Do espaço da experiência ao horizonte da expectativa:

\section{consciência da realidade e projeção de si}

É, portanto, nessa direção primeira de um ser-avir e de um ser-para que o eu se constrói como tendo-sido.

Christine Delory-Momberguer (2014, p. 64)

Nas escrituras dos sujeitos da pesquisa há um tempo sofrido e desejante (DELORY-MOBERGUER, 2014), intervalo de tempo que os separa de suas projeções; tempo em que são compreendidas as experiências de vida concretas e que, a partir das mesmas, é criado um horizonte de possibilidades para si. Ao narrarem as suas vidas, os educandos inauguravam um movimento que os levava adiante deles mesmos, ao inscreverem em seus registros o lugar onde desejavam e projetavam estar. Frederico escreve o seu tempo sofrido e desejante:

o que eu pretendo fazer faz parte de mim, vai além de apenas um "querer". Eu futuramente não me imagino fazendo algo que não é o que eu quero, creio que se isso acontecesse eu seria a pessoa mais infeliz do mundo. Minha vida eu creio que como em minha representação com o barbante seja uma reta ascendente, com pontos, porém, representando os desafios da vida pelos quais eu tenho que passar. Olhando para mim mesmo eu consigo ver o meu futuro, imaginar o meu futuro do jeito que eu gostaria que fosse e será, mas somente após eu passar pelos desafios que a vida impõe. Acredito que o que é meu já está guardado, porém só terei acesso quando a hora chegar, quando a minha hora chegar.

Através do barbante, tal como mencionado no subtítulo anterior, A fragilidade e a fortaleza: o (des)balanço da vida, os educandos simbolizaram a vida, os seus percursos, sua totalidade e sua trama. Frederico compreende o tempo que o separa do que ele imagina e dese- ja fazer no futuro como um tempo sofrido e desejante, repleto de desafios impostos pela vida e, ao mesmo tempo, "guardião" do projeto de si. O sentido do processo de biografização de si está, justamente, na possibilidade de propulsão do sujeito que se olha, se compreende e se desenha. O olhar para si, para o passado e para o presente, permite o olhar multifocal sobre a vida que, no intento de olhar para a frente, volta seu olhar para trás.

Os diferentes pontos focais direcionados sobre a vida estão presentes nos recortes narrativos de Tia Pesada, Loira e Rihana. Tia Pesada, ao lembrar de sua trajetória da infância, narra: "desde pequena eu queria ser enfermeira ou doutora, fazia a família me comprar roupas de enfermeira e doutora. Mas, não é isso o que quero hoje". No presente, Tia Pesada identifica que não há o mesmo gosto por ser enfermeira ou doutora. Em trecho subsequente, ela escreve: "quando eu era pequena eu brincava também de professora, passava horas escrevendo poemas e poesias. Essa é a minha paixão. Eu quero ser uma das melhores professoras de espanhol da FURG. É um sonho para mim fazer letras português/espanhol". Tia Pesada relembra os gostos da infância, de suas brincadeiras, e como isso produziu seus projetos de futuro. Ao evocar estas lembranças no presente, Tia Pesada percebe que alguns gostos permaneceram - "essa é a minha paixão" - e outros mudaram - "não é isso o que quero hoje". As compreensões dessas preferências, no presente, ajudaram-na a pensar e projetar o futuro.

De modo semelhante, Rihana evoca suas lembranças do passado, dizendo: "quando pequena sempre fui bem prestativa com minha família e colegas, por isso acho que medicina é uma opção para mim ajudar o próximo, ver que eu consigo realizar desejos de pessoas necessitadas e de bom caráter". Rihana articula seu desejo em tornar-se médica com as 
experiências que povoam sua infância, como forma de realizar-se e corresponder, através do tornar-se médica, às características que lembra de ter quando era pequena. Com Tia Pesada e Rihana, percebemos um movimento que revisita o passado e que, ao estabelecer o diálogo com os sentidos dessas memórias no presente, desloca-se para o futuro.

Agora, com a narrativa de Loira, há novos elementos para pensarmos. Ela parte do presente, dos sentidos que atribui ao que está vivenciando, para se projetar. Em sua escrita, ela coloca: "eu sou muito motivada em relação ao ingresso na universidade e cada dia mais me motivo. Um dos fatos que faz manter minha autoestima alta é o meu trabalho que, embora eu goste do que eu faça, eu sei que não é o que eu quero trabalhar no resto da minha vida". Loira realiza uma reflexão do hoje, através do trabalho que realiza, para fortalecer o que não quer ser. É a insatisfação em pensar sua vida na permanência do trabalho presente que a faz dizer a si que quer algo diferente para o futuro e, nesse sentido, projetar-se em direção à universidade.

Desta forma, é a compreensão de si, naquilo que se pode vir a ser, que instaura os sentidos do processo de reabertura do passado, “é um pouco como se o sentido da narrativa [...] não chegasse a determinar-se enquanto as suas buscas não fossem explicitadas" (JOSSO, 2010, p. 209). Neste decurso, o passado ajuda a compreender o presente. Ajudou Luiz, quando ele diz: "desde pequena sempre gostei de animais, então resolvi seguir essa profissão, porque nada melhor do que a gente fazer o que gosta". Auxiliou, igualmente, Adelaide Tavares e Roberta, quando elas narram, respectivamente: “ingressar na faculdade de Medicina seria a realização de um sonho, sempre me imaginei salvando vidas, diagnosticando problemas de saúde, assim ajudando as pessoas a terem uma qualidade de vida melhor"; "minha infância de certa forma me auxiliou na minha escolha profissional. Gostava de brincar de professora ou com meus brinquedos, ligados à área da Medicina (eu tinha uma boneca 'doente' e eu era sua enfermeira)". A visita ao passado também possibilitou compreensões de si a Lesiane, ao se perceber no presente e ao mirar-se para o futuro em aproximações e distanciamentos do passado, quando ela assim escreve: “quando criança que eu lembre não brincava muito de médica, adorava brincar de professora com as minhas bonecas, mas seria algo que eu não me imagino fazendo. Já médica, eu quero ser. Quando lembro das coisas que vivi, vejo que alguns gostos continuaram e outros acabaram se perdendo". Do mesmo modo, Luiz, Adelaide Tavares, Roberta e Lesiane escrevem as aprendizagens de um passado revisitado. As aprendizagens produzidas, no presente da narrativa, entre a memória revisitada e o futuro atualizado, induzido pela perspectiva temporal, fazem entrar em cena um sujeito reflexivo, autor ao pensar a sua existência.

O exercício da narrativa de si é o que promove o intercâmbio entre os tempos passado, presente e futuro. Pela narrativa, o sujeito revisita o passado mergulhado no presente e inventa um futuro. Assim, compreende-se enquanto sujeito inacabado e enovela o tempo com tramas que misturam passado, presente e futuro de forma que "temporalidade e narração formam um todo: o tempo é constituinte do significado" (ABRAHÃO, 2004, p. 220). É no decurso do processo de construção do tempo como um todo, onde o presente é articulado com o passado e com o futuro, que se inaugura a atividade autointerpretativa de tomada de consciência de si e da realidade na elaboração de um projeto de si, como continuidade de sua história.

Nas narrativas, aparece, também, um tempo presente que não estimula a projeção; um tempo presente marcado pelo medo do de- 
vir; um tempo mais sofrido do que desejante, relembrando Delory-Momberguer (2014). Em narrativa construída durante os primeiros encontros do segundo ciclo de atividades da disciplina "Construção do Projetos de Vida", quando a trajetória da infância foi ressignificada, Persistir narra:

Minha história no início, por exemplo, como criança foi bem legal. Há saudades de brincar de boneco, de carrinho, brincar de pega-pega e esconder, jogar futebol, ser inocente. Faria qualquer coisa para voltar a este passado e congelar para sempre. Na minha adolescência eu namorava bastante, tinha equilíbrio mental. Hoje já digo que nem estou vivo, pois errei muito e o desequilíbrio que governa a minha vida, desequilíbrio psicológico, perante a falta de pessoas sinceras a minha volta. Hoje não confio mais em ninguém. Tenho medo de ser adulto. Queria ser criança para sempre.

O trecho da narrativa de Persistir demonstra o receio pelo devir e o apego ao tempo passado, de onde ele situa o sentimento de saudade e onde gostaria de permanentemente conservar-se. Este excerto faz-nos pensar em Walter Benjamin, quando, em 1940, em sua IX tese sobre o conceito de história, descreve o chamado "Angelus Novus", obra do poeta e pintor Paul Klee. A descrição de Benjamin (1987, p. 226), diz:

Há um quadro de Klee que se chama Angelus Novus. Representa um anjo que parece querer afastar-se de algo que ele encara fixamente. Seus olhos estão escancarados, sua boca dilatada, suas asas abertas. 0 anjo da história deve ter esse aspecto. Seu rosto está dirigido para o passado. Onde nós vemos uma cadeia de acontecimentos, ele vê uma catástrofe única, que acumula incansavelmente ruína sobre ruína e as dispersa a nossos pés. Ele gostaria de deter-se para acordar os mortos e juntar os fragmentos. Mas uma tempestade sopra do paraíso e prende-se em suas asas com tanta força que ele não pode mais fechá-las. Essa tempestade o impele irresistivelmente para o futuro, ao qual ele vira as costas, enquanto o amontoado de ruínas cresce até o céu. Essa tempestade é o que chamamos progresso.

Tal como o anjo da história, Persistir não opta pelo futuro, para o qual está de costas. Se o anjo de Klee, na interpretação de Benjamin, gostaria de demorar-se no passado para reconstruir os fatos, Persistir quer congelá-lo para voltar a sentir-se inocente. Todavia, em outra narrativa, construída ao final das atividades do segundo ciclo de encontros, onde os educandos anunciaram seus projetos de vida ao grupo, Persistir registra: "eu quero ter mais vontade nas coisas que faço e possuir personalidade e coerência nos meus atos e se as coisas mudarem quero me desprender e seguir minha vida". Persistir, nesse outro momento de escrita de si, dá sinais de projeção ao dizer "eu quero ter", "possuir", “me desprender". Agora, parece-nos que Persistir se afasta da representação de si - como o anjo do quadro de Klee, voltado para o passado - e se desfaz do inconformismo com o vir a ser.

$\mathrm{Na}$ busca pela compreensão da projeção de si e da abertura ao futuro, encontramos em Josso (2010, p. 279) a descrição de que o projeto de si incorpora "duas noções subjacentes que permitem captar o lugar, o sentido e o estatuto epistemológico da própria noção de projeto". Trata-se da antecipação e da criatividade. A antecipação parte da compreensão do sujeito enquanto ser histórico, que se localiza no tempo. O sujeito, no seu reconhecimento enquanto ser produzido e produtor de história, desvela o tempo ao se lançar discursiva e reflexivamente. Neste reconhecimento, o sujeito antecipa o futuro, imaginando os componentes que atuam no desenrolar do tempo em direção aos projetos de si. As formas de expressão de si, elucidando os desejos e não desejos, referem-se à criatividade. A antecipação com a criatividade é que permite ao sujeito escolher o que quer tornar-se. É a ancoragem da antecipação e da criatividade na existência do ser 
que funda a noção de incompletude e inaugura o processo de projeção de si.

O Futuro Professor, ao produzir a sua história, antecipa o futuro na inventividade daquilo que deseja viver.

Meu gosto pelas letras me levou ao gosto pelas artes, pelas histórias que, fabulosamente, rimavam. Todo esse conjunto de palavras e fantasias, despertou em mim esse carinho e com o tempo, adquirindo um pouco mais de maturidade e discernimento, por que não espalhar isso? Então, todo aquele menino sonhador e encantado com as histórias da infância, contribui para que eu queira me tornar um educador e possa passar isso adiante e, assim, multiplicar esta paixão. É tão gratificante você ensinar e aprender ao mesmo tempo. Saber que sua capacidade de ganhar conhecimento e passá-lo adiante não está apenas movido pelo dinheiro. É lecionar por amor e dedicação. É obter realizações na sua carreira, é a coisa mais gratificante que se pode receber. Vai muito mais além do que apenas receber um salário relativo ao seu nível de estudo. É por amor ao que se faz. Saber que você vai ter colaborado com a vida de alguém e que irá marcar um pedacinho suas lembranças. É saber que você terá a chance de motivar pessoas a quererem mais e buscar por seus sonhos. É ter orgulho de dizer que é professor e que luta por um país melhor, abraçando este mundo gigantesco, mesmo com braços tão pequenos. É ter a vontade de mais, de querer, de buscar, de aprender... sempre.

O ser professor, é desenhado e antecipado com criatividade, é narrado com os sentidos que ocupam este ser na trajetória de uma vida. O Futuro Professor antecipa com criatividade o seu futuro, evoca o que quer ser, da maneira como imagina que será, aclarando as volições depositadas nessa projeção. O Futuro Professor não só quer mais para si, para a sua vida, quanto compreende que, ao ser professor, ele oportunizará que esse "ser mais" seja multiplicado. É a composição de um projeto que não se restringe à esfera individual; é um projeto de si, da sua vida adulta e profissional; mas é, também, projeto de uma vida social que ultrapassa a dimensão individual e que carrega, em seu sentido de ser, a dimensão coletiva.

Para finalizar, reconhecemos que a capacidade de se assumir portador de buscas é o que promove a emergência de uma história de vida e que faz com que o sujeito se impulsione na direção de um ser-a-vir, como nos fala o trecho citado em epígrafe (DELORY-MOMBERGER, 2014, p. 64). Na integração dos diferentes registros experienciais, evocados nas construções narrativas, é que se estabelece a liga entre o espaço da experiência e o horizonte projetivo de si.

\section{Considerações}

Chegamos ao final desta escrita na aproximação compreensiva da forma como os sujeitos do pré-universitário popular representaram a si, na medida daquilo que desejam ser. A representação do ser e a inventividade do porvir reside na soma entre o ato interpretativo, presente na forma-figura que representa o "estar sendo do sujeito", e o horizonte projetivo do narrador indivíduo-projeto, que se coloca em direção ao futuro com a representação do que quer ser (DELORY-MOMBERGER, 2014).

As trajetórias de vida revisitadas assumiram-se como criadoras de um espaço interior e exterior de produção do sujeito que pensou o viver na relação consigo e com o outro. A vida parece ter sido percebida pelos educandos como um lugar de formação, produção de conhecimento e de aprendizagens. Neste sentido, os conhecimentos produzidos podem ser compreendidos como elementos formativos, mobilizados pelos adolescentes e adultos educandos do Maxximus, sobre o repertório de suas experiências de vida. Os conhecimentos produzidos sobre a vida permitiram a compreensão sobre os seus conjuntos existenciais, marcados por fragilidades e fortalezas. As experiências partilhadas mostram-se como 
elementos não só mobilizados para representação de si, da totalidade de suas vidas, das experiências de fragilidade e de fortaleza, mas demonstraram o movimento empreendido pela produção de um conhecimento que thes permitiu encontrarem, em suas existências, as forças motrizes para os projetos que têm de si.

Diante disto, reconhecemos que há a reinvindicação de um outro sujeito. Um sujeito da educação que, imerso em um espaço educativo, não é somente assumido no horizonte dos processos escolares. Um horizonte que se revela, majoritariamente, preso ao conteúdo, a apropriação do conhecimento científico exigido, tradicionalmente, nos processos avaliativos e, da mesma forma, no exame de ingresso ao ensino superior. Aqui, o sujeito é pensando no horizonte da experiência, da vida vivida e da vida projetada. O sujeito é aquele marcado

\section{Referências}

ABRAHÃO, Maria Helena Menna Barreto. (Org.). A aventura (auto)biográfica: teoria e empiria. Porto Alegre: EDIPUCRS, 2004.

BENJAMIN, Walter. Magia e técnica, arte e política: ensaios sobre literatura e história da cultura. São Paulo: Brasiliense, 1987. (Obras Escolhidas, 1).

BUARQUE, Cristóvão. A universidade na encruzilhada. In: A universidade na encruzilhada. Seminário Universidade: por que e como reformar? Brasília: UNESCO Brasil, Ministério da Educação, 2003. p. 23-65.

DELORY-MOMBERGER, Christine. Biografia e educação: figuras do indivíduo-projeto. Natal: EDUFRN, 2014.

FREIRE, Paulo. Pedagogia do oprimido. Rio de Janeiro: Paz e Terra, 1987.

JOSSO, Marie-Christine. Experiências de vida e formação. Natal: EDUFRN; São Paulo: Paulus, 2010.

KUNDERA, Milan. A insustentável leveza do ser. São Paulo: Companhia das Letras, 2008.

MARQUES, Mario Osorio. Escrever é preciso: o prin- por esperanças e desesperanças, por sonhos, lutas e buscas e reconhecido por tais.

A vida é percebida e assumida como potencialmente formadora. As trajetórias de vida, quando refletidas por sujeitos da classe popular, revelam-se com possibilidades de desprendimento das amarras que sugerem ao sujeito popular determinações de futuro. $\mathrm{Na}$ negação a determinação, ao mito do destino, da permanência em determinados espaços porquê de origem popular, os sujeitos assumem-se como sujeitos produtores de história, de diferentes histórias. Os sujeitos se reconhecem como sujeitos condicionados, mas nunca determinados. E é, no reconhecimento das condições existenciais, como transitórias e mutáveis, os sujeitos se percebem como sujeitos de possibilidades, sujeitos inacabados, sujeitos de "ser mais".

cípio da pesquisa. Petrópolis, RJ: Vozes, 2008.

MELUCCI, Alberto. Juventude, tempo e movimentos sociais. In: FÁVERO, Osmar; SPÓSITO, Marília Pontes; CARRANO, Paulo; NOVAES, Regina Reys. (Orgs.). Juventude e contemporaneidade. Brasília: UNESCO, MEC, ANPEd, 2007. p. 29-46.

MORAES, Roque; GALIAZZI, Maria do Carmo. Análise textual discursiva. ljuí: Unijuí: 2013.

PASSEGGI, Maria da Conceição; ABRAHÃO, Maria Helena Menna Barreto; DELORY-MOMBERGER, Christine. Reabrir o passado, inventar o devir: a inenarrável condição biográfica do ser. In: ABRAHÃO, Maria Helena Menna Barreto; PASSEGGI, Maria da Conceição. (Orgs.). Dimensões epistemológicas e metodológicas da pesquisa (auto)biográfica. Tomo II. Natal: EDUFRN; Porto Alegre: EDIPUCRS; Salvador: EDUNEB, 2012. p. 29-57.

PESSOA, Fernando. Poesias. Porto Alegre: L\&PM, 1996.

Recebido em: 09/11/2016

Aprovado em: 24/03/2017 
Júlia Guimarães Neves é Doutoranda em Educação pela Universidade Federal de Pelotas - UFPel. Bolsista CAPES. e-mail: juliaaneves@hotmail.com

Endereço: Rua Barão do Triunfo, 91. São Lourenço do Sul - RS. CEP 96170.000. Telefone: (53) 991101477

Vilmar Alves Pereira é Doutor em Educação. Professor adjunto da Universidade Federal do Rio Grande - FURG. e-mail: vilmar1972@gmail.com

Endereço: Rua Dr. João Hugo Altmayer, 06 - Residencial Jardim do Sol. Rio Grande - RS.

CEP 96216.180.

Lourdes Maria Bragagnolo Frison é Doutora em Educação. Professora associada da Universidade Federal de Pelotas UFPel. e-mail: frisonlourdes@gmail.com

Endereço: Rua Eng. Rodolfo Ahrons 285. Porto Alegre - RS. CEP 91530.320. Telefone: (051) 99971.1408 